\title{
Correlation between sit-to-stand ability, dynamic balance, gait speed, and quality of life in stroke population: a non-randomized pilot study
}

\author{
Muhammad Azharuddin ${ }^{1 *}$ and Nayeem U. Zia ${ }^{2}$
}

\begin{abstract}
Background: "Sit to stand" being a prerequisite for walking, the inability of patients to perform it can result in institutionalization, impaired functioning and mobility in activities of daily living. There was a need to find out whether "sit to stand" ability correlates with gait speed, dynamic balance, and quality of life in stroke patients. It is a pilot study in which sixteen sub-acute and chronic stroke (> 6 months) patients aged 45 to 65 years with the ability to walk at least 10 m, Mini Mental State Examination (MMSE) score > 27 were included. Patients with musculoskeletal impairments of lower extremity which would affect walking were excluded from the study. Each patient performed five times sit to stand (5TSTS) from a standard chair and time taken was recorded. Timed up and go (TUG) test and 10-m walk test (10MWT) were used to measure the dynamic balance and gait speed respectively. Stroke Adapted Sickness Impact Profile-30 (SASIP-30) scale was used to determine the quality of life of the patients.

Results: Correlation between the outcomes of the variables was analyzed using Pearson correlation co-efficient. The 5TSTS scores showed strong positive correlation to TUG $(r=0.823, P<.000)$ and SASIP-30 $(r=0.841, P<.000)$. However, moderately strong negative relationship was found between 5TSTS and gait speed $(r=-0.639, P<.008)$.

Conclusion: The study concludes that change in the 5TSTS performance can affect motor functions like dynamic balance and gait as well as quality of life. Exercise training focusing on sit-to-stand ability may also influence activities of daily living (ADLs) after stroke.
\end{abstract}

Keywords: Cerebrovascular accident, Sit-to-stand ability, Balance, Quality of life, Time up and go

\section{Background}

Stroke has a significant impact on all components of functionality, and is the leading cause of disability [1]. The disabilities are manifested in the form of impairment of body function or body structure, activity limitation, and/or participation restriction [2]. Additional limitations including gait-related activities are seen in more than half of the stroke survivors [3], and the most

\footnotetext{
* Correspondence: md.azhar897@gmail.com

${ }^{1}$ Centre for Physiotherapy and Rehabilitation Sciences (CPRS), Jamia Millia

Islamia (A Central University), New Delhi 110025, India

Full list of author information is available at the end of the article
}

commonly cited concern after stroke is whether they will regain independent walking $[3,4]$. "Sit to stand" (STS) is biomechanically demanding, requiring lower extremity joint torque and range of motion than walking or stair climbing [5]. Standing up from a seated position is one of the most frequently performed functional tasks, and it is an essential pre-requisite to walking [6]. The ability to stand up without assistance is important for independent living [6] and preventing falls [7]. STS requires coordination between trunk and lower limb movements, muscle strength, and control of equilibrium and stability [8]. Due to the various impairments of post stroke, 
physiotherapists need to optimize patients' performance of motor tasks in everyday life. Thus, clinicians need a reliable and valid functional measurement that will correlate to the status of a patient's motor functions and functional mobility at baseline to monitor the patient's progress as a result of treatment [9].

STS movement skill can help researchers and clinicians determine the functional level of a patient. Assessment of the STS movement has been done using various quantitative and semi-quantitative techniques [10]. In the last two decades, studies have been published regarding the performance of STS [11], and it has been reported that stroke may result in the alteration of STS performance, which may be seen as asymmetry of body weight support and joint moments produced, asymmetry of joint kinematics, and alteration in amount of support needed [12]. Although the timed STS test has been used as an outcome measure in stroke rehabilitation, the relationship between muscle strength, exercise endurance, and balance performance and five times sit-to-stand (5TSTS) scores is still unclear [9].

TUG is a simple test to measure the mobility of an individual, which include static and dynamic balance [13]. Shumway-Cook et al. concluded that subjects who take longer than $14 \mathrm{~s}$ to complete the TUG have a higher risk for falls [14].

Ambulation ability has been correlated with gait speed; changes in gait speed that result in a transition to a higher category of ambulation classification resulted in better function and quality of life; ambulation ability that is predicted by gait speed is a reliable method of classifying patients. Walking speed predicts level of function i.e. walking is limited to home at $<0.4 \mathrm{~m} / \mathrm{s}$ and short community walks are feasible at $0.4-0.8 \mathrm{~m} / \mathrm{s}(0.9 \mathrm{mph})$. Community mobility requires walking speed $>0.8 \mathrm{~m} / \mathrm{s}(1.8 \mathrm{mph})$ [15].

Despite the frequent use of 5TSTS in various studies and found to be reliable, there is no study related to the patient's functional status. The study aimed to delineate possible associations of 5TSTS scores with balance ability measured using the timed up and go (TUG) test, gait speed measured by $10-\mathrm{m}$ walk test, and quality of life (QOL), in order to gain a better understanding of the content validity of the 5TSTS scores in the stroke population. If found correlated with dynamic balance, gait speed, and QOL, 5TSTS can serve as a reliable parameter for determining the functional status of stroke patients.

\section{Methods}

A pilot study with sixteen sub-acute and chronic stroke patients aged between 45 and 65 years $(56.19 \pm 7.98)$ with the ability to walk a distance of $10 \mathrm{~m}$ with or without using a walking aid were included. Patients were recruited from HAHC Hospital, New Delhi and nearby areas of Delhi. Patients with musculoskeletal impairments of the lower extremity, peripheral neuropathy, and other neurological disorders were excluded from the study. All the patients furnished written informed consent before participation in the study. The details of patient characteristics are depicted in Table 1. The study was approved by the Jamia Hamdard Institutional Ethics Committee (JHIEC), New Delhi, India.

\section{Procedure}

After the patients were enrolled, following measures were recorded starting with 5TSTS followed by TUG, 10MWT, and filling of Stroke Adapted Sickness Impact Profile-30 (SASIP-30) scale on the same day.

\section{Outcome measures}

\section{Five times sit-to-stand (5TSTS) test}

It is a reliable test in patients with stroke [16] and has a potential link with falls, strength of lower limbs, and even psychological measures [17]. For this test, the patients were given a practice trial and a minute of rest was allowed before the actual performance. Patients sat comfortably with leg well supported on the standard chair $(47 \mathrm{~cm})$ with a backrest. It was ensured the patient stood up completely (i.e., knee extension) and sat down (touched the chair) in the procedure. Standardized instructions were given as follows: "By the count of 3 , please stand up and sit down as quickly as possible for 5 times. Place your hands on your lap and do not use them throughout the procedure. Lean your back against the chair's backrest at the end of every repetition." The

Table 1 Patient characteristics. Values are expressed in mean \pm SD unless mentioned

\begin{tabular}{ll}
\hline Variables & Mean \pm SD \\
\hline Age (years) & $56.19 \pm 7.98$ \\
Height (cm) & $165.81 \pm 7.45$ \\
Weight (kg) & $64.56 \pm 9.37$ \\
BMI & $23.56 \pm 3.48$ \\
Duration of stroke (months) & $26.19 \pm 17.47$ \\
Co-morbidities, no. (\%) & \\
HTN & $5(31.25)$ \\
DM & $5(31.25)$ \\
CAD & $2(12.5)$ \\
Hypothyroidism & $2(12.5)$ \\
5TSTS (s) & $12.81 \pm 3.91$ \\
TUG (s) & $17.21 \pm 11.06$ \\
10 MWT (m/s) & $0.79 \pm 0.36$ \\
SASIP-30 & $29.69 \pm 21.15$ \\
\hline
\end{tabular}

HTN hypertension, DM diabetes mellitus, CAD coronary artery disease, 5TSTS five times sit to stand, TUG timed up and go test, 10MWT 10-m walk test, SASIP-30 Stroke Adapted Sickness Impact Profile-30 
timing started once the subject's back left the backrest and stopped once the back touched the backrest [9].

\section{Timed up and go (TUG) test}

Each patient stood up from a standard chair, walked a distance of $3 \mathrm{~m}$, turned, and walked back to the chair, and sat down. The amount of time taken was recorded (in seconds) with a stopwatch. The patients wore their regular footwear and used their customary walking aid (cane, walker) if needed. Each patient started with the back against the chair, and walking aid in hand [13].

\section{Ten-meter walk test (10MWT)}

The patients were instructed to walk $10 \mathrm{~m}$ without any physical assistance. A well-marked distance of $2 \mathrm{~m}$ was allowed at the start and at the end for the patient to accelerate and decelerate. The time was measured while the individual walked a distance of $6 \mathrm{~m}$. Speed $(\mathrm{m} / \mathrm{s})$ was determined by dividing the distance by the time taken to complete the distance [18].

\section{SASIP-30}

It is a scale to measure the QOL after stroke. The SASIP-30 consists of 8 subscales, viz., body care and movement, mobility, ambulation, social interaction, emotional behavior, alertness behavior, communication, and household management. Each of the 30 items is a statement describing a change in behavior that reflects the impact of illness on some aspect of daily life. Patients were asked to mark items most descriptive of themselves. The scores are also presented as a percentage of maximal dysfunction, ranging from 0 to $100 \%$. Higher scores indicate a less desirable health outcome. A total score of more than 33 indicates impairment in ADLs, inability to live independently, difficulty with self-care, and difficulty with mobility and performing their main activity [19].

\section{Statistical analysis}

Data collected were analyzed using the SPSS statistical software, version 11.0 (IBM SPSS Statistics). Correlation between values of 5TSTS (seconds), TUG (seconds), 10MWT $(\mathrm{m} / \mathrm{s})$, and SASIP-30 were done by applying Pearson correlation coefficient with a significance level of $p<0.05$ (2-tailed).

\section{Results}

The mean age of the patients was $56.19 \pm 7.98$ years. The mean duration of stroke was $26.19 \pm 17.47$ months (sub-acute and chronic patients). The mean weight and mean BMI were within normal ranges. But there were comorbidities present: Hypertension (HTN) [5], diabetes mellitus (DM) [5], coronary artery disease (CAD) [2], hypothyroidism [2]. Patient was taking medications for the comorbidities mentioned. The characteristics of the patients are shown in Table 1. After analysis, as shown in Fig. 1, the 5TSTS score showed strong positive correlation with TUG $(r=0.823, P<.001)$ and SASIP-30 $(r=$ $0.841, P<.001)$. However, there was a moderately strong negative relationship between 5TSTS and 10MWT $(r=$ $-0.639, P=.008)$. Also, TUG was negatively correlated with 10MWT $(r=-0.698, P=.003)$ and positively with QOL $(r=.745, P<.001)$ whereas gait speed and QOL were negatively correlated with each other $(r=0.576, P$ $=.019)$.

\section{Discussion}

The STS transition is one of the most important activities of daily living because people frequently use it as they move from sitting position to standing position and then often to walking [12]. There is scarcity of literature on relationship between sit-to-stand ability and other measures of functional independence. Therefore, the purpose of this study was to investigate relationship of 5TSTS with the dynamic balance, gait speed, and the quality of life in chronic stroke patients.

Lower limb strength and balance reactions of either or both lower extremities are required for a successful performance of the 5TSTS test, although contributions from individual legs cannot be differentiated [20]. The results of this study revealed a strong positive relationship between 5TSTS test and dynamic balance $(r=$ .823), which few studies have investigated in stroke population to date (Fig. 1A). Most of the research reported that the 5TSTS test to be more dependent on the strength of lower extremities [21, 22], although other factors like position of the foot and spasticity of planter flexors also affect the symmetry and weight distribution [23]. Lord et al. found out that in community-dwelling older people, one of the most contributing factors in the variation in STS is knee extensor strength [22]. Schenkman et al. found that strength was relatively more important than balance in predicting the performance of standing in functionally impaired older people [24]. Also, Weiss et al. demonstrated that strength is the key element in the improvement of STS performance during training in stroke survivors [25]. Our finding, on the other hand showed that performance of 5TSTS also depends on balance. This is in corroboration with the finding of a research that was done by Shamay in which no significant correlation between 5TSTS scores and the muscle strength index but to balance after demographics were controlled. Performance on STS ability explains the dynamic balance which in turn affects the risk of falls in chronic stroke patients [9]. This was shown by one controlled trial study, i.e., different levels of sit-to-stand training can help improve dynamic standing balance control, particularly toward the anterior direction, which 


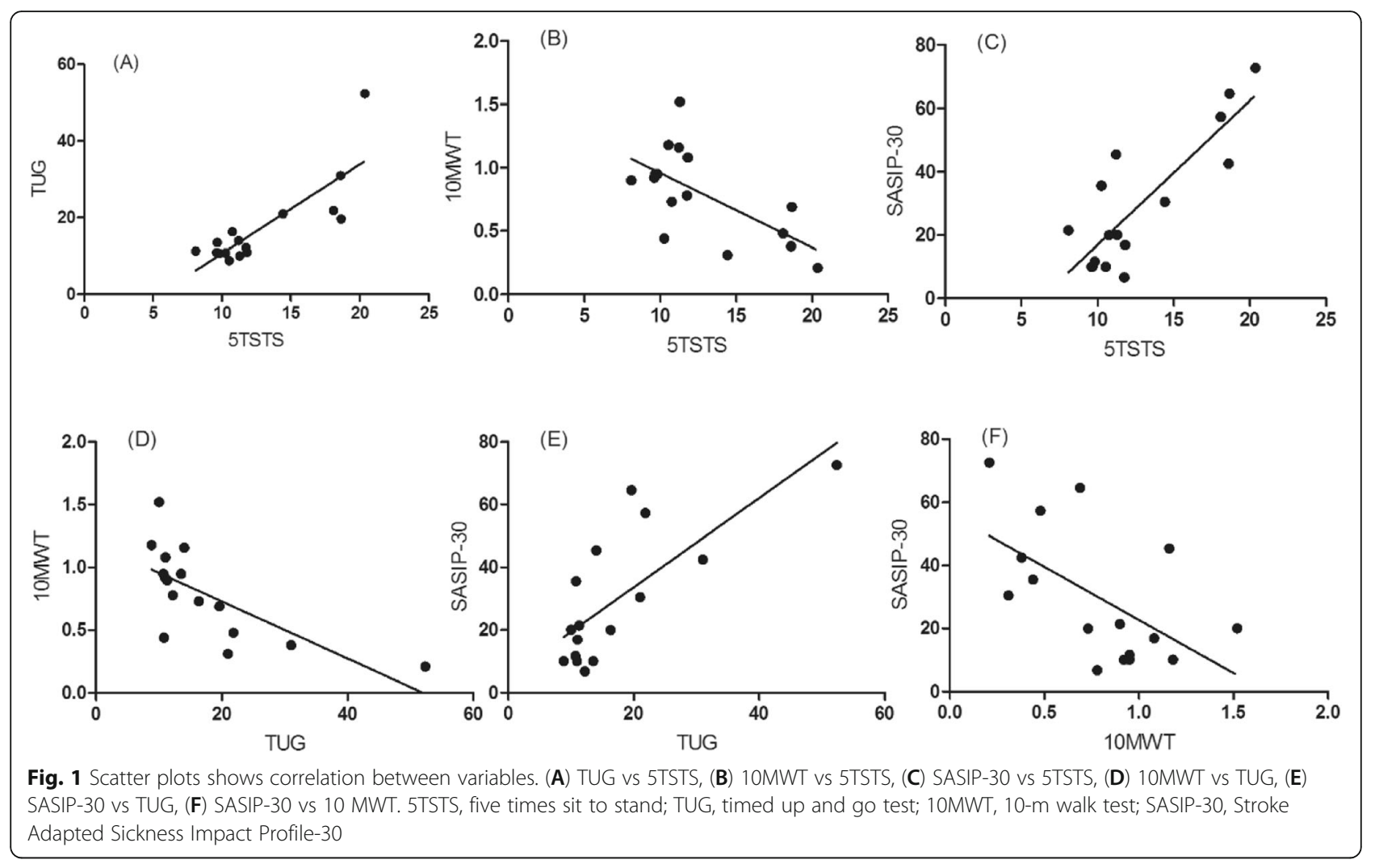

is the most frequently demanded in daily life [26]. A similar finding was seen in study done by Pieper et al. who found high correlation between 5TSTS and TUG. They suggested that these physical performance measures may be interchangeable in their ability to predict physical functioning in these clinical groups despite differences in test demands [21]. The results of studies are found to be conflicting whether the performances of 5TSTS is dependent on strength or balance because of the difference in baseline function of subjects and/or specific differences in the type and length of the exercise training protocol [25].

Another striking finding of this study is that the 5TSTS was found to have a moderately strong negative relation with the gait speed (Fig. 1B). Gait speed, in turn, determines balance and functional independence in stroke patients. Gait velocity is a valid and reliable measure of walking recovery after stroke and is considered to be a valuable indicator of functional status of an individual. Schmidt et al. concluded that gait velocity gain that transition to a higher class of ambulation results in better function and quality of life, especially with regard to mobility and community participation in initial household ambulators [15]. Studies have shown that speed-dependent training help improve STS ability as this activity requires the generation of a vertical force equal to body weight in a fraction of a second. This may hasten independence, because faster force generation results in more effective use of available strength [27]. Bowden et al. conducted a study in chronic stroke patients to validate the speed-based classification system with quantitative measures of walking performance. It was found out that stroke patients who had gait speed less than $0.4 \mathrm{~m} / \mathrm{s}$ were more likely to be household ambulators, between 0.4 and $0.8 \mathrm{~m} / \mathrm{s}$ were limited community ambulators [28].

The results of our study revealed that gait speed is negatively correlated with quality of life $(r=-.576)$, and 5TSTS test is highly positively correlated with SASIP-30 $(r=.841)$ after stroke (Fig. 1F). Therefore, performance of chronic stroke patients on 5TSTS test can give an insight into the patients' level of ambulation and overall quality of life. Moreover, community mobility has a direct relationship with the social life of stroke patients which in turn may impact their quality of life.

Usually, in clinical practice, a therapist administers a variety of tests to assess the physical status of stroke patients which is often time consuming and physically demanding. The relationship of the 5TSTS and other variables shown indicate that 5TSTS can help in evaluating other motor functions, i.e., 5TSTS is a multidimensional test. For example, if a stroke patient does not perform well on 5TSTS test, administering TUG test may not be needed as these measures correlate well with each other. Establishing a relationship between these variables can be validated further. 
There are limitations in the study. The number of subjects is small and thus the data cannot be generalized to population. We used convenient sampling so the baseline characteristics of the subjects are not uniform. We did not consider the spasticity of the lower limb, which can affect the performance, though only ambulatory patients were included. Future studies can be done on larger samples and an intervention that may improve STS ability henceforth improving the stroke patients' motor and ADL functions.

\section{Conclusions}

The changes in STS ability can affect balance and walking speed. Due to strong correlation between these variables, the 5TSTS performance can be used as an indicator of the independence in stroke patients. Therapeutic interventions that focused on the "sit-to-stand" ability might give benefits in dynamic balance and quality of life.

\section{Acknowledgements}

The authors acknowledge the patients for their participation and cooperation in the study.

\section{Authors' contributions}

MA and NZ have contributed in study design, literature search, data analysis, and review. MA has contributed in data collection, manuscript preparation, and editing. The authors have read and approved the final manuscript.

\section{Funding}

There was no funding support for this study from any external sources for recruitment of subjects, publication, or any process.

\section{Availability of data and materials}

The data collected and/or analyzed related to the study are available from the corresponding author on reasonable request and after institutional approval.

\section{Declarations}

\section{Ethics approval and consent to participate}

The study was approved by The Jamia Hamdard Institutional Ethics Committee (JHIEC), New Delhi, India. Reference number (not applicable). Informed written consent was obtained from each patient included in the study, and the study protocol conforms to the ethical guidelines.

\section{Consent for publication}

Yes, all the authors provide consent for the publication of this study in this journal.

Authors declare that the abovementioned manuscript has not been published or considered for publication elsewhere.

\section{Competing interests}

The authors declare that they have no competing interests.

\section{Author details}

${ }^{1}$ Centre for Physiotherapy and Rehabilitation Sciences (CPRS), Jamia Millia Islamia (A Central University), New Delhi 110025, India. ${ }^{2}$ Physiotherapist, Directorate of Health Services Kashmir, Kashmir, Jammu and Kashmir, India.
Received: 10 December 2020 Accepted: 18 July 2021

Published online: 26 October 2021

\section{References}

1. Ivey FM, Hafer-Macko CE, Macko RF. Exercise rehabilitation after stroke. NeuroRx. 2006;3(4):439-50. https://doi.org/10.1016/j.nurx.2006.07.011.

2. Cerniauskaite M, Quintas R, Koutsogeorgou E, Meucci P, Sattin D, Leonardi $\mathrm{M}$, et al. Quality-of-life and disability in patients with stroke. Am J Phys Med Rehabil. 2012;91(13):S39-47. https://doi.org/10.1097/PHM.0b013e31823d4df7.

3. Dobkin BH. Clinical practice. Rehabilitation after stroke. N Engl J Med. 2005; 352(16):1677-84. https://doi.org/10.1056/NEJMcp043511.

4. Kollen B, Kwakkel $G$, Lindeman E. Longitudinal robustness of variables predicting independent gait following severe middle cerebral artery stroke: a prospective cohort study. Clin Rehabil. 2006;20(3):262-8. https://doi.org/1 $0.1191 / 0269215506 \mathrm{cr} 9100 \mathrm{a}$.

5. Lomaglio MJ, Eng JJ. Muscle strength and weight-bearing symmetry relate to sit-to-stand performance in individuals with stroke. Gait Posture. 2005; 22(2):126-31. https://doi.org/10.1016/j.gaitpost.2004.08.002.

6. Alexander NB, Galecki AT, Nyquist LV, Hofmeyer MR, Grunawalt JC, Grenier $M L$, et al. Chair and bed rise performance in ADL-impaired congregate housing residents. J Am Geriatr Soc. 2000;48(5):526-33. https://doi.org/1 0.1111/j.1532-5415.2000.tb04999.x.

7. Cheng PT, Wu SH, Liaw MY, Wong AM, Tang FT. Symmetrical body-weight distribution training in stroke patients and its effect on fall prevention. Arch Phys Med Rehabil. 2001;82(12):1650-4. https://doi.org/10.1053/apmr.2001.26256.

8. Boukadida A, Piotte F, Dehail P, Nadeau S. Determinants of sit-to-stand tasks in individuals with hemiparesis post stroke: a review. Ann Phys Rehabil Med. 2015;58(3):167-72. https://doi.org/10.1016/.j.rehab.2015.04.007.

9. Ng S. Balance ability, not muscle strength and exercise endurance, determines the performance of hemiparetic subjects on the timed-sit-tostand test. Am J Phys Med Rehabil. 2010;89(6):497-504. https://doi.org/10.1 097/PHM.0b013e3181d3e90a.

10. Janssen WG, Bussmann HB, Stam HJ. Determinants of the sit-to-stand movement: a review. Phys Ther. 2002;82(9):866-79. https://doi.org/10.1093/ ptj/82.9.866.

11. Faria CD, Saliba VA, Teixeira-Salmela LF. Musculoskeletal biomechanics in sitto-stand and stand-to-sit activities with stroke subjects: a systematic review. Fisioterapia em movimento. 2010;23(1):35-52. https://doi.org/10.1590/5010351502010000100004

12. Perry SB, Marchetti GF, Wagner S, Wilton W. Predicting caregiver assistance required for sit-to-stand following rehabilitation for acute stroke. J Neurol Phys Ther. 2006;30(1):2-11. https://doi.org/10.1097/01.NPT.0000282144.72 703.cb.

13. Steffen TM, Hacker TA, Mollinger L. Age-and gender-related test performance in community-dwelling elderly people: six-minute walk test, Berg Balance Scale, timed up \& go test, and gait speeds. Phys Ther. 2002; 82(2):128-37. https://doi.org/10.1093/ptj/82.2.128.

14. Shumway-Cook A, Brauer S, Woollacott M. Predicting the probability for falls in community-dwelling older adults using the Timed Up \& Go Test. Phys Ther. 2000;80(9):896-903. https://doi.org/10.1093/ptj/80.9.896.

15. Schmid A, Duncan PW, Studenski S, Lai SM, Richards L, Perera S, et al. Improvements in speed-based gait classifications are meaningful. Stroke. 2007;38(7):2096-100. https://doi.org/10.1161/STROKEAHA.106.475921.

16. Mong Y, Teo TW, Ng SS. 5-repetition sit-to-stand test in subjects with chronic stroke: reliability and validity. Arch Phys Med Rehabil. 2010;91(3): 407-13. https://doi.org/10.1016/j.apmr.2009.10.030.

17. Lord SR, Murray SM, Chapman K, Munro B, Tiedemann A. Sit-to-stand performance depends on sensation, speed, balance, and psychological status in addition to strength in older people. J Gerontol Series A. 2002; 57(8):M539-43. https://doi.org/10.1093/gerona/57.8.M539.

18. Green J, Forster A, Young J. Reliability of gait speed measured by a timed walking test in patients one year after stroke. Clin Rehabil. 2002;16(3):30614. https://doi.org/10.1191/0269215502cr495oa.

19. de Haan RJ VSA, Van den Bos GA LM. Clinical meaning of the StrokeAdapted Sickness Impact Profile-30 and the Sickness Impact Profile-136. Stroke. 2000;31:2610-5.

20. Sibella F, Galli M, Romei M, Montesano A, Crivellin M. Biomechanical analysis of sit-to-stand movement in normal and obese subjects. Clin Biomech (Bristol, Avon). 2003;18(8):745-50.

21. Pieper B, Templin TN, Goldberg A. A comparative study of the five-times-sitto-stand and timed-up-and-go tests as measures of functional mobility in 
persons with and without injection-related venous ulcers. Adv Skin Wound Care. 2014;27(2):82-92. https://doi.org/10.1097/01.ASW.0000442876.94332.26.

22. Lord SR, Murray SM, Chapman K, Munro B, Tiedemann A. Sit-to-stand performance depends on sensation, speed, balance, and psychological status in addition to strength in older people. The Journals of Gerontology Series A: Biological Sciences and Medical Sciences. 2002;57(8):M539-43.

23. Jung KS, In TS, Cho HY. Effects of sit-to-stand training combined with transcutaneous electrical stimulation on spasticity, muscle strength and balance ability in patients with stroke: a randomized controlled study. Gait Posture. 2017;54:183-7. https://doi.org/10.1016/.gaitpost.2017.03.007.

24. Schenkman M, Hughes MA, Samsa G, Studenski S. The relative importance of strength and balance in chair rise by functionally impaired older individuals. J Am Geriatr Soc. 1996;44(12):1441-6. https://doi.org/10.1111/j.1 532-5415.1996.tb04068.x

25. Weiss A, Suzuki T, Bean J, Fielding RA. High intensity strength training improves strength and functional performance after stroke. Am J Phys Med Rehabil. 2000;79(4):369-76. https://doi.org/10.1097/00002060-20000700000009.

26. Tung FL, Yang YR, Lee CC, Wang RY. Balance outcomes after additional sitto-stand training in subjects with stroke: a randomized controlled trial. Clin Rehabil. 2010;24(6):533-42. https://doi.org/10.1177/0269215509360751.

27. Porter MM. Power training for older adults. Appl Physiol Nutr Metab. 2006: 31(2):87-94. https://doi.org/10.1139/h05-034.

28. Bowden MG, Balasubramanian CK, Behrman AL, Kautz SA. Validation of a speed-based classification system using quantitative measures of walking performance poststroke. Neurorehabil Neural Repair. 2008;22(6):672-5. https://doi.org/10.1177/1545968308318837.

\section{Publisher's Note}

Springer Nature remains neutral with regard to jurisdictional claims in published maps and institutional affiliations.

\section{Submit your manuscript to a SpringerOpen ${ }^{\circ}$ journal and benefit from:}

- Convenient online submission

- Rigorous peer review

- Open access: articles freely available online

- High visibility within the field

- Retaining the copyright to your article

Submit your next manuscript at $\boldsymbol{\nabla}$ springeropen.com 